\title{
DETECTION OF MALIGNANCY IN SOLITARY THYROID NODULE.
}

\section{Ibrahim M. Mustafa M.D., Mohamed S. Abood M.D.,Abd El Rahman H.Sadiq M.D. and EmanA.El Tokhy M.Sc. \\ General Surgery department,Faculty of Medicine, Zagazig University}

\begin{abstract}
Background: The presence of a solitary thyroid nodule is a risk factor for malignancy. The major challenge in management of the solitary thyroid nodule remains the assessment to which nodules require surgical excision and which can be followed conservatively. The fine needle aspiration cytology (FNAC) is one of the most important advances in the management of the thyroid nodules, it has an accuracy rate greater than 90\%. Objective: to assess the predictive value of conventional clinical examination, laboratory investigation and cytology (fine needle aspiration cytology (FNAC) and histopathology) in the diagnosis of malignancy in the solitary thyroid nodule and its impact on the development of a surgical policy for proper management.

Patients and methods:a total of 100 patients with solitary thyroid nodules were thoroughly examined clinically after taking detail history and FNAC; all the patients were subjected to surgery after preoperative preparation and anesthesia checkup. Thyroidectomy specimen was evaluated by histopathologicalexamination .

Exclusion criteria: multinoduler goiter, hypo and hyperthyroidism, patients refuse FNAC, other investigation and patients unfit for surgery .

Statistical analysis: SPSS version 11. Results:In the present study both FNAC and histopathology was done in 100 patients of solitary thyroid nodule. Out of 100 cases, 86 cases were benign and 14 cases were malignant on histopathology. On cytology 84 cases were benign, 11 cases were malignant, and five cases were suspicious smear, two of them were (follicular adenoma) false positive case. Sensitivity was $100 \%$, specificity was $97.6 \%$, accuracy was $98 \%$,positive predictive value was $87.5 \%$ and negative predictive value was $100 \%$.Conclusion: Significant proportion of solitary thyroid nodule (14\%) was malignant. So, careful assessment of thyroid nodule is important for early diagnosis. All cases with solitary thyroid nodules should have FNAC as pre-operative diagnostic method to reduce the number of patients referred for surgery.

Keywords:Solitary thyroid nodule.FNAC, Histopathology.
\end{abstract}

\section{INTRODUCTION}

Solitary thyroid nodule is a single discrete mass Oof abnormal tissue in an otherwise normal thyroid gland $^{(1)}$.

True solitary thyroid nodule (STN) is rather a common disease occurs in $4-7 \%$ of the adult population based on palpation and of $20-76 \%$, based on ultrasound examination ${ }^{(2)}$.

The presence of a solitary thyroid nodule is a risk factor for malignancy. The reported incidence of carcinoma in solitary thyroid nodules varies from 2$20 \%^{(3)}$.

However thyroid carcinoma closely resembles its benign counterpart in physical characteristics, measurable physiological parameters such as serum T3/T4 levels and ultrasonic characteristics. Therefore the surgical excision of the nodule and its histopathological examination is the only way to differentiate between the more benign and much less frequent malignant nodules. Since most of the nodules are benign, symptomless and small in size, they do not require surgical excision. ${ }^{(4)}$

FNAC has becoming a common diagnostic procedure replacing other diagnostic methods as it requires no anaesthesia, it is easy to perform and can be repeated without much discomfort to the patient and has a high diagnostic accuracy. ${ }^{(4)}$

\section{Objective}

to assess the predictive value of conventional clinical examination, laboratory investigation and cytology (fine needle aspiration cytology (FNAC) and histopathology) in the diagnosis of malignancy in the solitary thyroid nodule and its impact on the development of a surgical policy for proper management.

\section{PATIENTS AND METHODS}

This prospective study was represented randomly on 100 patients who were complaining from solitary thyroid swelling who were selected from outpatient clinic of general surgery department of Zagazig University Hospitals in the period from June 2010 to June 2013.

\section{Exclusion criteria:}

Multinoduler goiter, hypo and hyperthyroidism, patients refuse FNAC, other investigation and patients unfit for surgery.

100 cases of solitary thyroid nodules were thoroughly examined clinically after taking detail history,thyroid function tests along with ultrasound scan, and X-ray neck and all patients were subjected to FNAC by palpation (suction technique) using 20 gauge needle. Smears were prepared, and fixed by using $95 \%$ ethyl alcohol. And then stained by papanicolua's method and the cytological diagnosis 
was made. The smears were classified into the following categories: inadequate, benign, malignant and suspicious.

After FNAC, all the patients were subjected to surgery [Hemi-thyroidectomy for benign smears, Total thyroidectomy was performed in malignant cases without lymphadenopathy and in suspicious smears and Total thyroidectomy with selective neck dissection for malignant cases if there is positive lymph nodes] after preoperative preparation and anaesthesia check up.

Thyroidectomy specimen was evaluated by histopathological examination. Specimens were

\section{RESULTS}

Table (1): The age and sex distribution of our cases.

\begin{tabular}{llll}
\hline Age & Male & Female & Total \\
\hline $10-20$ & 0 & 01 & 01 \\
\hline $21-30$ & 5 & 19 & 24 \\
\hline $31-40$ & 8 & 24 & 32 \\
\hline $41-50$ & 6 & 21 & 27 \\
\hline $51-60$ & 2 & 09 & 11 \\
\hline More than 60 & 2 & 03 & 05 \\
\hline Total & $\mathbf{2 3}$ & $\mathbf{7 7}$ & $\mathbf{1 0 0}$ \\
\hline
\end{tabular}

Table (2) :The clinical presentation of our cases.

\begin{tabular}{lll}
\hline Clinical presentation & No & $\%$ \\
\hline Swelling & 100 & $100 \%$ \\
\hline Pain referred to ear & 3 & $3 \%$ \\
\hline Dysphagia & 6 & $6 \%$ \\
\hline Dyspnea & 4 & $4 \%$ \\
\hline Hoarseness of voice & 2 & $2 \%$ \\
\hline Lymphadenopathy & 9 & $9 \%$
\end{tabular}

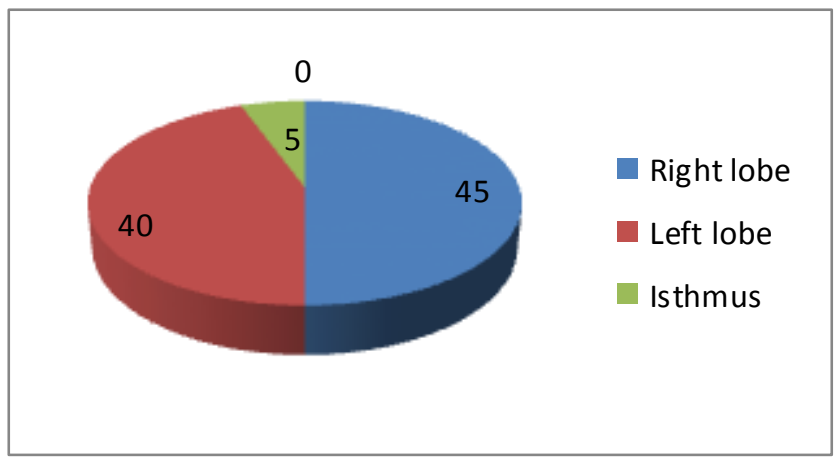

Figure (1): The site of the nodules in our cases. 


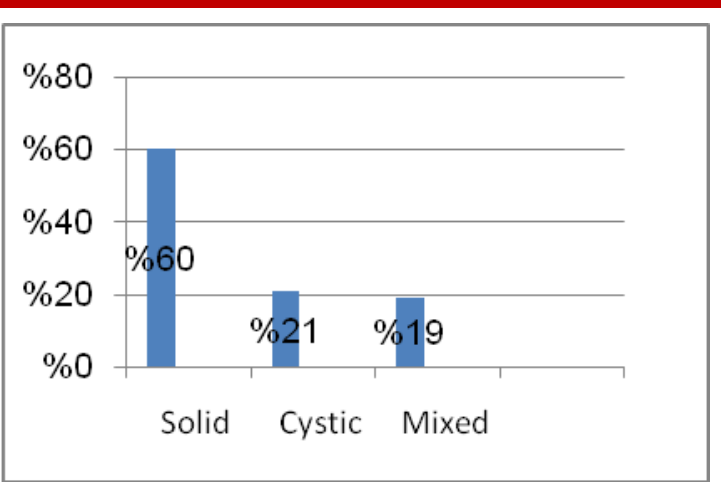

Figure (2):Findings of ultrasonic examination of our cases.

Table (3) : The relation between the size of the solitary thyroid nodules of our cases and the histopathological examination.

\begin{tabular}{llll}
\hline Size & Benign group & $\begin{array}{l}\text { malignant } \\
\text { group }\end{array}$ & P value \\
\hline$<2 \mathbf{c m}$ & 25 & - & 0.57 \\
\hline$>\mathbf{2 ~ c m}$ & 61 & $\mathbf{1 4}$ & \\
\hline
\end{tabular}

Table (4): The results of cytology after FNAC

Most the studied smears $(80 \%)$ were benign; but four cases showed inadequate smears even through taking different punctures by palpation so the technique was repeated again but guided with ultrasound and the results were benign . The total benign smears were $(84 \%)$

\begin{tabular}{lll}
\hline The results of cytology & N & \% \\
\hline Benign & 84 & $84 \%$ \\
\hline Malignant & 11 & $11 \%$ \\
\hline Suspicious & 5 & $5 \%$ \\
\hline
\end{tabular}

Table (5): Surgical management of our cases.

\begin{tabular}{lll}
\hline Operation type & No. & $\mathbf{\%}$ \\
\hline Hemi- thyroidectomy & 84 & $84 \%$ \\
\hline Total thyroidectomy with selective LN dissection & 09 & $09 \%$ \\
& & \\
\hline Total thyroidectomy & 07 & $07 \%$ \\
\hline Total & $\mathbf{1 0 0}$ & $\mathbf{1 0 0 \%}$ \\
\hline
\end{tabular}


Table (6): The histopathological findings of excised specimens and the incidence of different pathology

\begin{tabular}{|c|c|c|}
\hline Histopathological type & No. & $\%$ \\
\hline Colloid nodule & 80 & $80 \%$ \\
\hline Papillary carcinoma & 9 & $9 \%$ \\
\hline Follicular carcinoma & 3 & $3 \%$ \\
\hline Anaplastic carcinoma & 2 & $2 \%$ \\
\hline Follicular adenoma & 02 & $02 \%$ \\
\hline Non specific thyroiditis & 04 & $04 \%$ \\
\hline Total & 100 & $100 \%$ \\
\hline
\end{tabular}

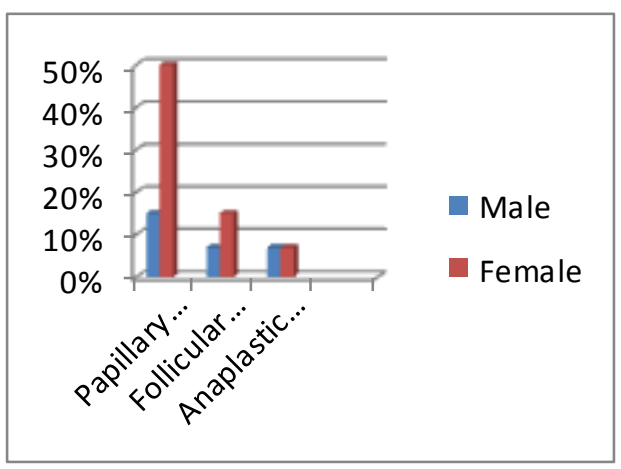

Figure (3):Frequency of malignancy in relation to sex.

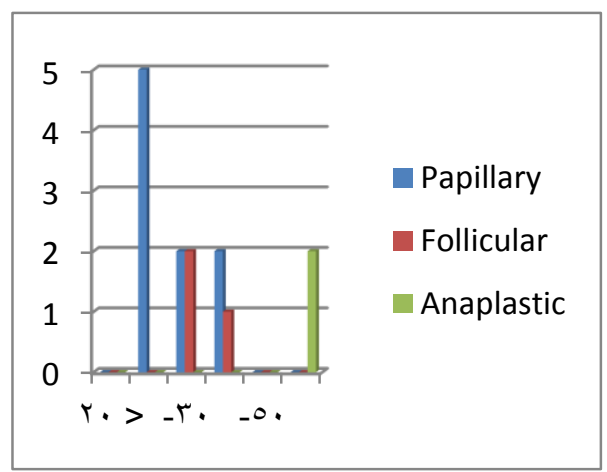

Figure (4):Frequency of malignancy in relation to age.

Table (7): The relation between FNAC and histopathological examination in diagnosis of solitary thyroid nodule of our cases.

\begin{tabular}{llllll}
\hline & FNAC & $\begin{array}{l}\text { Histopathological } \\
\text { examination }\end{array}$ & $\mathbf{X}^{2}$ & $\begin{array}{l}\text { P } \\
\text { Value }\end{array}$ \\
\hline Benign & $\mathbf{8 4}$ & $\mathbf{8 4}$ & 66.35 & $<0.001$ \\
\cline { 1 - 3 } Malignant & 11 & 11 & & \\
\cline { 1 - 4 } $\begin{array}{l}\text { Folliculr } \\
\text { lesion } \\
(5)\end{array}$ & Adenoma & Suspicious & $\mathbf{0 2}$ & & \\
\cline { 2 - 4 } Total & Carcinoma & Suspicious & $\mathbf{0 3}$ & & \\
\hline
\end{tabular}


SENSITIVITY AND SPECIFICITY OF THE STUDY

TP-True positive, FP-False positive, TN-True negative, FN-False negative

TP-14, FP-2,TN-84, FN-0

Sensitivity $=\mathrm{TP} /(\mathrm{TP}+\mathrm{FN}) \mathrm{X} 100,=100 \%$

Specificity $=\mathrm{TN} /(\mathrm{TN}+\mathrm{FP}) \mathrm{X} 100,=97.6 \%$

Positive predictive value $=\mathrm{TP} /(\mathrm{TP}+\mathrm{FP}) \quad \mathrm{X} 100$ $=87.5 \%$

Negative

predictive

value $=\mathrm{TN} /(\mathrm{TN}+\mathrm{FN}) \mathrm{X} 100=100 \%$

Accuracy rate $=\mathrm{TP}+\mathrm{TN} / \quad(\mathrm{TP}+\mathrm{TN}+\mathrm{FP}+\mathrm{FN}) \quad \mathrm{X} 100$ $==98 \%$

\section{DISCUSSION}

This prospective study was carried out to detect malignancy in 100 cases presented with solitary thyroid nodule and its impact on the development of a surgical policy for proper management.

The age range from 19 to 66 years with mean of age is 35.2 years. The highest age incidence was found to be in the fourth decade of life (32 patients) and much less below 20and above 60 years. This is similar with the other studies.Huque et $\mathbf{a l}^{(2)}$;Rains and Charles ${ }^{(5)}$

In this study, out of 100 patients, male were $23(23 \%)$ and female were $77(77 \%)$. Male: female ratio is 1: 3.35 . This is similar with the other studies.Huque et $\mathbf{a l}^{(2)}$;Sattar et $\mathbf{a l}^{\left({ }^{(6)}\right.}$

Regarding presenting complaints we have found that all of the patients with neck swelling presents within variable durations. Some patient also presented with other symptoms like cervical lymphadenopathy in (9) patients, dysphagia in (6) patients, dyspnea in (4) patients, pain referred to ear in (3) patients,

and hoarsenessof voice in (2) patients. It is well supported by others studies Khan et al ${ }^{(7)}$;Tarrar et al $^{(8)}$.

In this study, we have seen that right lobe is slightly more affected than left lobe. There is yet no reported predilection for any specific site and no reason has been put forward for such a predilection. We found 45 nodules in right lobe, 40 nodules in left lobe and 5 nodules in isthmus which is consistent with other studies on STNs Huque et al $^{(2)}$ ;Gupta et al ${ }^{(9)}$;Tabaqchali et al $^{(10)}$.

Ultrasonographic study revealed $60 \%$ solid nodules, $21 \%$ cystic nodules and $19 \%$ were mixed nodules.Malignancy was found more in hard nodule $9(64.3 \%)$. It is almost similar to other studies.Huque et al $^{(2)}$; Tarrar et al ${ }^{(8)}$. Here hardness of nodule was due to malignancy and inflammatory

conditions.

Thyroid nodule size is routinely measured, although its impact on thyroid cancer risk is unclear. In this study: all malignant lesions were more than 2 $\mathrm{cm}$. However, it differs from the studies of Tai et $\mathbf{a l}^{(\mathbf{1 2})}$ revealed that there was no great significance between nodule size larger than $4 \mathrm{~cm}$ and nodule size less than $4 \mathrm{~cm}(P=0.5)$ and in Kamranet al $^{(11)}$ revealed that, below 1 cmIncreasing thyroid nodule size impacts cancer risk in a nonlinear fashion but threshold is detected at $2.0 \mathrm{~cm}$, beyond which cancer risk is unchanged.

Fine needle aspiration cytology (FNAC) is very important, highly sensitive and minimally invasive preoperative diagnostic tool. We divided our FNAC cases into four groups: inadequate, benign, malignant, suspicious. Inadequate smears (4) were repeated guided with ultrasound then the results were benign smears, and suspicious smears (5) as FNAC cannot distinguish between follicular adenoma and follicular carcinoma. FNAC diagnosis of this study was supported by postoperative histopathological report.

Final diagnosis in this study was on the basis of histopathological confirmation. Non malignant cases were 86 patients $(86 \%)$. The commonest was colloid nodule 80 cases $(80 \%)$ followed by the non specific thyroiditis (4\%) and the least were follicular adenoma 2 cases (2\%). which is compatible with other studies.AlRobbani $^{(1)}$;Chetan et al ${ }^{(3)}$;Gupta et al ${ }^{(9)}$.However, it differs from the studies of Tai et $\mathbf{a l}^{(\mathbf{1 2})}$ simpleadenoma had the highest incidence of non malignant cases.

Malignantcases found in 14 cases (14\%).In this study among 14 malignant cases ,9casess (64\%) were papillary carcinoma, 3 cases $(21 \%)$ were follicular carcinoma and 2 cases (14\%) were anaplastic carcinoma .It shows a clear predominance of papillary over follicular and anaplastic carcinoma .It is almost similar to other studies Chetan et al ${ }^{(3)}$; Tarrar et al ${ }^{(8)}$.It was reported in a study that papillary carcinoma comprises about $60 \%$ of all thyroidcancer and follicular carcinoma comprises $18 \%$ of all malignant thyroid neoplasmKrukowski ${ }^{(13)} ;$.Robins ${ }^{(14)}$.

In this study: carcinoma of thyroid gland may be diagnosed in patients of all ages, but most cases are seen in the 3rd to 5th decades and females were predominant (10/14) and female-male ratio was 2.5 


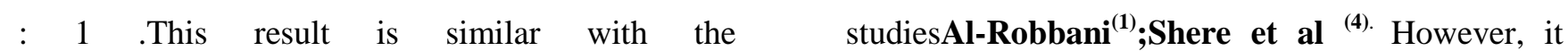
otherstudies.Huque et $\mathbf{a l}^{(2)}$ ;Chandanwale ${ }^{(15)}$;Ergete and Abebe ${ }^{(16)}$

In this study the percentage of sensitivity, specificity, and accuracy was $100 \%, 97.6 \%, 98 \%$ respectively. This result is similar with the other differs from the studies of Gupta et $\mathbf{a l}^{(\mathbf{9 )} \text {, the }}$ sensitivity, specificity and accuracy was $80 \%$, $86.6 \%, 84 \%$ respectively and in Musani et al $^{(17)}$ was $61.5 \%, 98.9 \%, 94.3 \%$ respectively .

Table (8): The post-operative complication in comparison to the operative technique

\begin{tabular}{|c|c|c|c|c|c|}
\hline & Hemi-T & $\begin{array}{l}\text { Total T.\& } \\
\text { LNs. }\end{array}$ & $\begin{array}{l}\text { Total } \\
\text { T }\end{array}$ & $\mathrm{X}^{2}$ & $\mathrm{P}$ value \\
\hline No. of pts/operation & 84 & 9 & 7 & \multirow{7}{*}{6.8} & \multirow{7}{*}{0.24} \\
\hline Hemorrhage & 1 & - & - & & \\
\hline Infection & 2 & - & - & & \\
\hline Seroma & 1 & 2 & - & & \\
\hline Hypoparathyroidism & - & 2 & 1 & & \\
\hline $\begin{array}{l}\text { Recurrent laryngeal } n \text {. } \\
\text { injury }\end{array}$ & - & 1 & - & & \\
\hline $\begin{array}{l}\text { External laryngeal } n . \\
\text { injury }\end{array}$ & - & - & $\overline{1}$ & & \\
\hline
\end{tabular}

Complications occurred after total thyroidectomy with neck dissection was (56\%) (two patient had tetany, one had recurrent laryngeal nerve injury and two had seroma ), after total thyroidectomy was (29\%) (One had tetany and one had low pitched sound) and Complications occurred after Hemithyroidectomy was (5\%) had complications: (one had reactionary heamorrage, two had postoperative infection and one seroma). Thus, the type and the extent of the operation are to be considering as a major risk factor for developing complications. This result is similar with the other studies. AlRobbani $^{(1)}$; Ali et al $^{(18)}$.

\section{CONCLUSION}

Significant proportion of solitary thyroid nodule (14\%) was malignant. So, careful assessment of thyroid nodule is important for early diagnosis.

All cases with solitary thyroid nodules should have FNAC as pre-operative diagnostic method to reduce the number of patients referred for surgery.

\section{REFERENCES}

1-Al-Robbani AM (2013): Study of Thyroid Carcinoma in Solitary Thyroid Nodule, In :(Dinajpur Med Col J 2013 Jan; 6 (1):58-63).

2- Huque SM, Ali MI, Huq $M$ et al (2012): Histopathological pattern of malignancy in solitary thyroid nodule, Bangladesh J Otorhinolaryngol 2012; 18(1): 5-10.

3- Chetan RV, Veeresalingam B, Kumar KM, et al (2013): A study on the clinical manifestations and the incidence of benign and malignant tumors in a solitary thyroid nodule, In: Int J Res Med Sci. 2013 Nov;1(4):429-434.

4- Shere SK, Kulkarni AS, Phulgirkar PP et al (2013): Correlation of fine needle aspiration cytology with histopathology in diagnosis of thyroid lesions. In: journal of evolution of medical and dental science, vol, 12.issue, 26.july, 2013.pages; 4826-4831.

5- Rains AJH, Charles VM.(2004): The thyroid and parathyroid glands. In: Bailey and Love's short practice of surgery, edited by Williams NS, Bulstrode C and O'Connell PR (Eds) Twent third ed. London, ELBS, 2004; 707 -733.

6- Sattar MA, Alam MR \& Haider A(2003):. Clinicopathological study of solitary cold thyroid nodule, Bangladesh J Otorhinolaryngol. 2003; 9(1): $24-27$

7- Khan SA, Gafur SA, Khan MK, et al (2012): Pattern of malignancy in clinically solitary thyroid nodule, Mymensingh Medical Journal :MMJ, [2012, 21(1):17]

8- Tarrar AM, Khan OU, Wahla MS (2010): SOLITARY THYROID NODULE; FREQUENCY OF MALIGNANCY AT COMBINED MILITARY HOSPITAL RAWALPINDI. Professional Med J Dec 2010; 17(4): 598-602.

9- Gupta M, Gupta S, Gupta VB (2010): Correlation of fine needle aspiration cytology with histopathology in the diagnosis of solitary thyroid nodule. J Thyroid Res 2010; 2010:379051

10- Tabaqchali MA, Hasan JM, Johnson ST, Wadhera V(2000): Thyroid aspiration cytology in Newcastle: a six year cytology/histology correlation study. Amr Coll Surg Engl 2000;82:149. 
11-Kamran SC, Marqusee E, Kim MI et al(2013):Thyroid Nodule Size and Prediction of Cancer,In: The Journal of Clinical Endocrinology \& Metabolism February 1, 2013 vol. 98 no. 2 564-570

12- Tai JD, Yang JL, Wu SC et al (2012): Risk factors for malignancy in patients with solitary thyroid nodules and their impact on the management. J Can Res Ther 2012;8:379-83

13- Krukowski ZH (2005) : The thyroid gland and thyroglossal tract; Baily and love's short practice of surgery ,edited by Williams NS, Bulstrode C and O'Connell PR (Eds) ; 24th edn. London, 2005; 797 98

14- Robins SL, Cotran US, Kumar V(2004):Pathological Basis of Disease, edited by Robins SL, Cotran US, Kumar V; 6th ed.Philadelphia, WB Saunders Company 2004; $1201-1225$.
15- Chandanwale S, Singh N, Kumar H, Pradhan P, Gore C, Rajpal M(2012). Clinicopatholological correlation of thyroid nodules. Int J Pharm Biomed Sci 2012, 3(3), 97-102.

16- Ergete W and Abebe D (2002): Discordance rate between thyroid FNAC \&histopathology diagnosis. Ethiopian J Health Dev. 2002;16:227.

17- Musani MA, Khan FA, Malik S et al (2011): FINE NEEDLE ASPIRATION CYTOLOGY: SENSITIVITY AND SPECIFICITY IN THYROID LESIONS, J Ayub Med Coll Abbottabad 2011;23(1)

18- Ali AM, Elkadi TT, Ali MM, Ali EM (2013): Total/near-total versus hemi-thyroidectomy for low risk well differentiated thyroid cancers: A retrospective study. In: Egyptian Journal of Surgery Vol. 32, No. 1, January 2013. 